\title{
Association of Resistance of Neisseria gonorrhoeae to Killing by Human Phagocytes with Outer-membrane Proteins of About 20 Kilodaltons
}

\author{
By N. J. PARSONS, ${ }^{1}$ A. A. A. KWAASI ${ }^{1}$ P. V. PATEL,${ }^{1}$ P. M. V. MARTIN ${ }^{2}$ \\ AND H. SMITH ${ }^{1 *}$ \\ 1 Department of Microbiology, University of Birmingham, PO Box 363, Birmingham B15 2TT, UK \\ ${ }^{2}$ Unité d'Ecologie Bactérienne, Institut Pasteur, Paris, France
}

(Received 14 June 1984 ; revised 15 October 1984)

\begin{abstract}
The determinant(s) of gonococcal resistance to killing by human phagocytes has been extracted from outer membrane vesicles (OMV) of a phagocyte-resistant strain, BS4 (agar), with sodium cholate $(1 \%, w / v)$. The extracts, like the OMV, nullified the effect of antiserum raised against whole BS4 (agar) to promote intracellular killing of the latter by human peripheral blood phagocytes. Fractionation of the extract on Sephadex G75 produced an active fraction with much less protein and lipopolysaccharide (LPS) than in the original extract. Furthermore, crude LPS prepared from the resistant gonococci was inactive. These results imply that the factor(s) promoting intracellular resistance is a protein. SDS-PAGE of the active fraction suggested that the factor was not a principal outer membrane protein nor one of three proteins previously thought to be associated with resistance. In contrast to a similar preparation from a phagocytesusceptible strain, BSSH, the active fraction from BS4 (agar) showed faintly staining proteins in the regions of 20 and $60 \mathrm{kDal}$. When eluted from the gels, the former but not the latter neutralized the above effect of antisera, thus associating the $20 \mathrm{kDal}$ protein(s) with resistance to intracellular killing.
\end{abstract}

\section{INTRODUCTION}

In previous work (Parsons et al., 1981, 1982) the determinant of the resistance of an in vivoselected strain of Neisseria gonorrhoeae, BS4 (agar), to killing by human phagocytes was shown to be not pili but to reside in purified outer membrane vesicles (OMV). The determinant was detected on the reasonable working hypothesis (Veale et al., 1978; Parsons et al., 1981) that it neutralized an antiserum raised against whole, live gonococci of strain BS4 (agar), which abolished the resistance of this strain to intracellular killing by human phagocytes; and also by the capacity of an antiserum raised against a putative determinant to similarly nullify the intracellular resistance of strain BS4 (agar) (Parsons et al., 1981). Three proteins, A, B and C, in the purified OMV from BS4 (agar) were thought to be associated with its resistance to phagocyte killing, since they were not present in the OMV from a closely related, phagocyte-susceptible strain, BSSH (Parsons et al., 1982).

This paper describes the extraction of the determinant from the OMV with sodium cholate (Heckels, 1977), its partial fractionation and biological and chemical analysis of the products.

\section{METHODS}

Micro-organisms. Neisseria gonorrhoeae BS4 (agar) is a strain relatively resistant to killing by human phagocytes which was selected from a laboratory strain, BS (Kellogg type 2, small colony forming, pilated), by four passages

Abbreviations: HHS, heated human serum; KDO, 2-keto-3-deoxyoctonate; LPS, lipopolysaccharide; OMV, outer membrane vesicles. 
through plastic chambers implanted subcutaneously in guinea pigs and minimal culture on agar medium (Penn $e t$ al., 1976, 1977; Parsons et al., 1979). Strain BSSH, a strain susceptible to killing by phagocytes and constituting the majority of the population of strain BS was selected from the latter in vitro by its 'single highlight' (SH) colony form (Penn et al., 1977). Both strains were grown, stored and counted as described previously (Veale et al., 1975; Penn et al., 1976, 1977).

Extraction of crude $O M V$ with sodium cholate. OMV were extracted from strain BS4 (agar) (100 ml; $10^{11}$ bacteria $\mathrm{ml}^{-1}$ ) in $1 \mathrm{M}$-lithium chloride as described previously (Parsons et al., 1982). Sedimented OMV were resuspended in glycine/ $\mathrm{NaOH}$ buffer, $0 \cdot 1 \mathrm{M}, \mathrm{pH} 9.5$ (approx. $20 \mathrm{ml}$ ) containing sodium cholate $(1 \%, \mathrm{w} / \mathrm{v}$ ) and agitated in $50 \mathrm{ml}$ Erlenmeyer flasks with glass beads $\left(3 \mathrm{~mm}\right.$ diameter; 2 beads $\left.\mathrm{ml}^{-1}\right)$ on an orbital shaker $\left(60\right.$ cycles $\left.\mathrm{min}^{-1}\right)$ for $1 \mathrm{~h}$ at $37^{\circ} \mathrm{C}$. Undissolved OMV were removed by centrifugation $\left(100000 \mathrm{~g}, 1 \mathrm{~h}, 4^{\circ} \mathrm{C}\right)$ and the extract was fractionated immediately.

Fractionation of cholate extract. The extract $(3-4 \mathrm{ml})$ containing about $1000 \mu \mathrm{g}$ protein $\mathrm{ml}^{-1}$ and derived from $5 \times 10^{11}$ gonococci $\mathrm{ml}^{-1}$, was applied to a column ( $1 \mathrm{~m}$ long, $15 \mathrm{~mm}$ diameter) of Sephadex G75 (Pharmacia) and eluted with the same buffer as that used for extraction (flow rate, $10 \mathrm{ml} \mathrm{h}^{-1}$ ). Elution was followed by monitoring $A_{279}$. Appropriate fractions (each of $2 \mathrm{ml}$ ) were pooled and concentrated by negative pressure dialysis to the original volume of the extract $\left(\equiv 5 \times 10^{11}\right.$ gonococci $\left.\mathrm{ml}^{-1}\right)$ applied to the column.

Extraction of lipopolysaccharide (LPS). The method of Westphal \& Jann (1965) was used. Approximately $4 \mathrm{~g}$ wet weight of strain BS4 (agar) (approx. $1 \times 10^{13}$ organisms) were suspended in $20 \mathrm{ml}$ 4.8 M-phenol, vortex-mixed with 20 glass beads for $10 \mathrm{~min}$ at room temperature and then heated to $60^{\circ} \mathrm{C}$ for $10 \mathrm{~min}$. The mixture was cooled to $4^{\circ} \mathrm{C}$ and the bacteria removed by centrifugation $\left(10000 \mathrm{~g}, 10 \mathrm{~min}, 4^{\circ} \mathrm{C}\right)$. The top aqueous layer was retained and the middle and lower layers were re-extracted with distilled water, volume equal to the aqueous layer removed. The combined aqueous phases were pooled, centrifuged $\left(20000 \mathrm{~g}, 10 \mathrm{~min}, 4^{\circ} \mathrm{C}\right)$ and dialysed against running tap water at room temperature for 2-3d. The retentate was treated with 3 vols of ice-cold dry acetone. The LPS precipitate (approximately $50 \mathrm{mg}$ ) was collected by centrifugation $(4000 \mathrm{~g}, 10 \mathrm{~min}$, room temperature), redissolved in distilled water at a concentration equivalent to $2 \times 10^{12}$ gonococci $\mathrm{ml}^{-1}$ and dialysed against distilled water for $14-15 \mathrm{~h}$ at room temperature. The product was not purified further; it contained some protein (see Results) and probably small amounts of nucleic acid and peptidoglycan.

SDS-P AGE. The method of Laemmli (1970) was used, with modifications described by Parsons et al. (1982). For protein profiles, the samples $(50 \mu \mathrm{l})$ applied were of concentrations equivalent to $5 \times 10^{11}$ gonococci ml ${ }^{-1}$, thus relating the results to the biological tests which were done on the same concentrations or simple multiples of them. Cytochrome $c$, horse myoglobin, bovine chymotrypsinogen A, ovalbumin, BSA and ovotransferrin $(12,17,26,45$, 66 and $77 \mathrm{kDal}$ respectively) were used as standards to indicate approximate molecular weights of protein. For separating the components of fraction $1 \mathrm{~b}$ (Fig. 2), $50 \mu \mathrm{l}$ aliquots of the fraction, equivalent to $2 \times 10^{12}$ organisms, were electrophoresed in each of seven channels on a $12.5 \%(\mathrm{w} / \mathrm{v})$ acrylamide gel as described by Parsons $e t$ al. (1982). Two regions (approx. $2 \mathrm{~cm}$ ) of the gel corresponding roughly to proteins of 20 and $60 \mathrm{kDal}$, and the region corresponding to the principal outer membrane proteins (around $35 \mathrm{kDal}$ ), were located by reference to a previous analytical gel; also two channels of the gel were stained in retrospect to confirm the location of the three regions. These regions from the remaining five channels were excised and each was macerated in an equal volume (2-3 ml) of phosphate buffered saline (PBS; Penn et al., 1976) with a pestle and mortar. The gel was removed by centrifugation $(2000 \mathrm{~g}, 5 \mathrm{~min}$, room temperature) and the extract concentrated by negative pressure dialysis to the original volume $(5 \times 50 \mu \mathrm{l})$ that had been applied to the gel. Thus, the whole volume was equivalent to $1 \times 10^{13}$ organisms and $1 / 10$ th was used to absorb the antiserum against whole gonococci (see below). For controls, $2 \mathrm{~cm}$ portions of the gel preceding the marker dye were treated similarly.

Assays of 2-keto-3-deoxyoctonate (KDO), protein and carbohydrate. Assays for KDO and protein (with BSA as standard) were as described by Parsons et al. (1982). Carbohydrate was estimated by the anthrone method (Trevelyan \& Harrison, 1952) using glucose as standard.

Indirect tests for the determinant of resistance to intracellular killing: pretreatment of strain BS4 (agar) with unabsorbed and absorbed antisera prior to phagocytosis tests. In summary, an antiserum against live organisms of strain BS4 (agar) drastically reduced the capacity of this strain to survive intracellularly in human phagocytes but the relevant antibody could be neutralized by prior absorption with extracts or with OMV containing the putative determinant of resistance to intracellular killing (Parsons et al., 1981, 1982).

Rabbit antiserum to strain BS4 (agar) was raised by multiple intravenous injections of live organisms in Trypticase Soy Broth (Baltimore Biological Laboratories) as described by Veale et al. (1978). For absorption with crude OMV (Table 1), equal volumes of antiserum and suspension of OMV ( $\equiv 5 \times 10^{11}$ gonococci $\left.\mathrm{ml}^{-1}\right) \mathrm{were}^{-}$ mixed and allowed to stand overnight at $4^{\circ} \mathrm{C}$. Absorption with the LPS preparations (Table 2) was done similarly with concentrations equivalent to $2 \times 10^{12}$ gonococci $\mathrm{ml}^{-1}$. The cholate extract of OMV and its fractions from the Sephadex column (Fig. 1, Table 1) were mixed at a concentration equivalent to $5 \times 10^{11}$ gonococci $\mathrm{ml}^{-1}$ with an equal volume of antiserum, kept at $4^{\circ} \mathrm{C}$ for $5 \mathrm{~h}$ and dialysed overnight at $4{ }^{\circ} \mathrm{C}$ against PBS (Penn et al., 1976) to remove free sodium cholate. The concentrated eluates $\left(25 \mu 1 \equiv 1 \times 10^{12}\right.$ gonococci) from each area of the SDSPAGE gels (Table 3) were mixed with antiserum $(100 \mu \mathrm{l})$ and allowed to stand overnight at $4{ }^{\circ} \mathrm{C}$. 
Gonococci [BS4 (agar), $2 \times 10^{7} \mathrm{ml}^{-1}$ ] were incubated $\left(1 \mathrm{~h}, 37^{\circ} \mathrm{C}\right)$ in Parker medium 199 containing $10 \%(\mathrm{v} / \mathrm{v})$ heated $\left(56^{\circ} \mathrm{C}, 30 \mathrm{~min}\right)$ human serum (HHS) obtained from defibrinated blood and $1 \%(\mathrm{v} / \mathrm{v})$ rabbit antiserum against live strain BS4 (agar) or the corresponding concentration of absorbed antiserum (see above). Antiserum was omitted from control samples. After incubation, the medium was then removed by centrifugation $(2000 \mathrm{~g}$, $3 \mathrm{~min}$, room temperature) and after washing three times with fresh medium (1 ml) without antiserum, the gonococci were suspended at a concentration of $2 \times 10^{6} \mathrm{ml}^{-1}$ in Parker medium 199 containing HHS (10\%, v/v) for mixing with phagocytes in the Leighton tubes.

As formerly (Parsons et al., 1981, 1982), phagocytosis tests used strain BS4 (agar) pretreated with the antiserum absorbed with a single concentration of the fraction containing the putative determinant. This concentration was equivalent to a standard number $\left(5 \times 10^{11}\right)$ of organisms extracted. The requirement for many replicates in the phagocytosis tests and the need to repeat each experiment several times to establish a single point (Parsons et al., 1981), precluded routine examination of several dilutions of the standard concentrations. Infrequently, dilutions were tested, and sometimes when loss of material could have occurred in a procedure, such as in the preparation of the LPS and gel eluates, materials were examined at concentrations 2-4 times the standard level (see above).

The other test for the determinant of resistance to intracellular killing was to raise an antiserum against the putative determinant and to see if it abolished the capacity of strain BS4 (agar) to survive intracellularly, as did the antiserum against whole organisms (Parsons et al., 1981, 1982). Antisera for this purpose were raised against fraction $1 \mathrm{~b}$ from the Sephadex column (Fig. 1) as follows. Rabbits received three subcutaneous injections of fraction $1 \mathrm{~b}$ (each $\equiv 10^{10}$ gonococci) at 10 -d intervals. The first two were given emulsified with an equal volume of Freund's complete adjuvant. Blood was collected and sera were prepared $14 \mathrm{~d}$ after the third injection. This antiserum was used to pretreat strain BS4 (agar) as described above for the antiserum raised against whole gonococci.

Test for the resistance of gonococci to intracellular killing. The test was a modification of that used previously to demonstrate intracellular survival of gonococci selected in vivo (Witt et al., 1976a, b; Penn et al., 1977; Veale et al., 1978; Parsons et al., 1981).

After treatment with antisera as described above, the treated and control suspensions of gonococci $(0 \cdot 5 \mathrm{ml}, 2 \times$ $10^{6} \mathrm{ml}^{-1},>60 \%$ viable) were mixed in Leighton tubes with an equal volume of suspensions of human phagocytes $\left(2 \times 10^{6} \mathrm{ml}^{-1}\right.$, about $80 \%$ PMN phagocytes) prepared from fresh human peripheral blood as described by Witt $e t$ al. $(1976 b)$ and suspended in Parker medium 199 with HHS $(10 \%, \mathrm{v} / \mathrm{v})$. After incubation for $1 \mathrm{~h}$ at $37^{\circ} \mathrm{C}$, the medium was discarded and the infected phagocyte deposit washed three times with PBS containing BSA $(0 \cdot 1 \%$, $w / v)$. The following determinations were made on the infected phagocytes. The number of gonococci per phagocyte (phagocytic index) seen microscopically on stained films on coverslips placed on the flat surface of the Leighton tubes was determined as described by Veale et al. (1975) and Witt et al. (1976a, b). The number of phagocytes in the deposits from Leighton tubes was determined from their content of DNA (Parsons et al., 1981). The washed deposits were scraped off with a rubber-tipped glass rod and suspended in $75 \mu 10 \cdot 1 \%$ (w/v) BSA in PBS. Suspensions from three replicate tubes were pooled and $20 \mu \mathrm{l}$ removed for an immediate viable count of gonococci (see below). The remaining pooled phagocyte suspension was treated with $5 \mathrm{M}-\mathrm{NaOH}(50 \mu \mathrm{l})$ for $1 \mathrm{~h}$ at $37^{\circ} \mathrm{C}$ and then with indole reagent (indole, $0.02 \%, \mathrm{w} / \mathrm{v}$, in $5 \mathrm{M}-\mathrm{HCl}, 250 \mu \mathrm{l}$ ) for $10 \mathrm{~min}$ at $100^{\circ} \mathrm{C}$. Cooled samples were extracted with chloroform $(1 \mathrm{ml})$ by vortex mixing $(30 \mathrm{~s})$ and the $A_{490}$ (in a Pye-Unicam SP 1800 spectrophotometer) of the aqueous phase obtained by centrifugation $(3000 \mathrm{~g}, 10 \mathrm{~min}$, room temperature) was read against a blank of $0 \cdot 1 \%(w / v)$ BSA in PBS after reaction with the indole reagent. The number of phagocytes on the surface of the Leighton tube (4-20 $\times 10^{4}$ in most tests) was obtained from a standard curve relating $A_{490}$ to numbers of phagocytes obtained from 12 different donors (Parsons et al., 1981). The number of viable gonococci in the phagocyte deposits was obtained by plating the $20 \mu \mathrm{l}$ sample of the suspension used for DNA assay (see above). The viable counts were corrected for settled non-cell-associated gonococci by deducting the low viable counts ( $<10 \%$ of those in tubes containing phagocytes) found in control tubes without phagocytes. The results were expressed (Tables 1,2 and 3) as the percentage of the total cell-associated gonococci (the product of the phagocytic index and the total number of phagocytes) that were viable.

Clearly, the presence of a few settled gonococci in control tubes indicates that some extracellular gonococci are present in the phagocyte deposits despite their thorough washing. However, extensive electron microscopy carried out when the phagocytosis tests were being established with strain BS (Witt et al., 1976a, b) and with a strain selected from BS by three passages [cf. BS4 (agar)] through guinea pig chambers, using a phagocyte : gonococci ratio of $1: 1$ (Witt et al., 1976a) showed that almost all (295 of 299 counted) cell-associated gonococci were intracellular. This predominantly intracellular habitat and the lack of significant extracellular adherence using guinea pig selected strains similar to BS4 (agar) and a 1:1 phagocyte:gonococci ratio has been checked periodically during the development of the work (Penn et al., 1977; Veale et al., 1978) and by us for BS4 (agar). Hence, with the control on the settled non-cell-associated gonococci (see above), the survival of predominantly intracellular gonococci after the $1 \mathrm{~h}$ phagocytosis period is indicated by the percentage viability of the cellassociated gonococci. Any suggestion that the action of the antiserum in stimulating the intracellular killing of BS4 (agar) (Tables 1, 2 and 3) may be due to opsonization of extracellular gonococci is discounted; $(a)$ by the electron 
microscopic evidence for the predominantly intracellular habitat of the gonococci; and $(b)$ by the lack of a consistent increase in phagocytic index for the antiserum-treated organisms compared with untreated organisms. The latter was noted and discussed in the initial experiments on antiserum treatment (Veale et al., 1978) and is seen routinely in the phagocytosis tests. For examples, in experiments 1 to 6 in Table 1, the phagocytic indices (the number of gonococci per phagocyte) used to calculate the percentage viable gonococci in the phagocyte deposits were $0.52,0.32,0.49(\operatorname{expt~} 1) ; 0 \cdot 31,0 \cdot 16,0.36(\operatorname{expt} 2) ; 0.35,0.46,0.39(\operatorname{expt} 3) ; 0 \cdot 70,0.38,0.28(\operatorname{expt} 4) ; 0.23,0.14$, 0.14 (expt 5); and $0.31,0.76,0.36$ (expt 6) for the untreated gonococci, the gonococci treated with unabsorbed antiserum, and the gonococci treated with antiserum absorbed with cholate extract respectively.

All influence of extracellular bacteria on the results could be eliminated by determining the percentage viability of the cell-associated gonococci after killing all extracellular gonococci with fresh human serum and antibiotic as had been done in experiments that established intracellular survival and growth of gonococci (Veale et al., 1979; Casey et al., 1979). In the opening stages of the investigation of the determinants of intracellular survival (Parsons et al., 1981), comparisons were made between the results obtained by the method described above and those gained after deposits of infected phagocytes were incubated for $2 \mathrm{~h}$ in tissue culture medium containing spectinomycin $\left(20 \mu \mathrm{g} \mathrm{ml}^{-1}\right)$ and fresh human serum $(10 \%$, w/v) which killed extracellular gonococci (Casey et al., 1979). The results were similar, indicating that antiserum increased intracellular killing, but not when it was absorbed with surface washes of strain BS4 (agar). The longer test was not suitable for routine examination of samples from fractionations of surface washes.

These indirect phagocytosis tests for the determinants of intracellular survival are not rigidly quantitative for the reasons stated previously (Witt et al., 1976b) but they demonstrate valid differences in intracellular survival of strain BS4 (agar) after various treatments. The tests give variable results and only by repeating them on many batches of material were unequivocal results achieved. The results presented are from representative experiments; the variable viability of gonococci in phagocyte deposits from different donors on different days precluded the presentation of mean values and standard errors.

\section{RESULTS}

\section{Extraction of antiserum-neutralizing components from $O M V$ by sodium cholate $(1 \%, w / v)$}

The results of experiments 1 and 2 in Table 1 show that substantial material with antiserumneutralizing activity was extracted from crude OMV of BS4 (agar) by the procedures described in Methods. The protein, carbohydrate and KDO contents of the cholate extract indicated almost complete solubilization of the OMVs. The high figure for extractable protein relative to that of the crude OMV may have been due to the fact that not all the protein of the latter reacted in the assay.

\section{Fractionation of the sodium cholate extract on Sephadex G75}

The profile $\left(A_{279}\right)$ of a typical fractionation of the cholate extracts is shown in Fig. 1. The antiserum-neutralizing activities of the cholate extract and fractions 1a, 1b, 2 and 3 for two experiments typical of 17 are shown in Table 1 (expts 3 and 4). The results of all 17 experiments indicated that the antiserum-neutralizing activities of fractions $1 \mathrm{a}$ and $1 \mathrm{~b}$ were roughly equal. Thus, both fractions were active in all experiments and the number of times (9) when fraction $1 \mathrm{~b}$ appeared slightly more active than fraction $1 \mathrm{a}$ (as in Table 1) was almost equal to that (8) when the position was reversed. Also, in a few tests four- and fivefold dilutions of the standard concentrations of both fractions $1 \mathrm{a}$ and $1 \mathrm{~b}$ were inactive, indicating the absence of gross differences between them. Fractions 2 and 3 contained little activity. Fraction $1 \mathrm{~b}$ contained much less protein than fraction la but the amounts of carbohydrate in the two fractions were similar and usually less than those found in the cholate extract and fractions 2 and 3 . Experiments in which only the whole cholate extract and fraction $1 \mathrm{~b}$ were examined (expts 5 and 6, Table 1) support the above results. Analysis for KDO indicated that $20-40 \%$ of the original LPS was present in fraction $1 b$.

In summary, fraction $1 \mathrm{~b}$ was as active as fraction $1 \mathrm{a}$ and contained much less protein. Also, an antiserum raised against it reduced the resistance of BS4 (agar) to killing by phagocytes. Thus, in one phagocytosis test typical of five, the viable gonococci in the phagocyte deposits after $1 \mathrm{~h} \mathrm{at}$ $37^{\circ} \mathrm{C}$, calculated as a percentage of the total visible organisms, were $9.7,1.7$ and 2.8 for untreated BS4 (agar), BS4 (agar) treated with antiserum to whole organisms, and BS4 (agar) treated with antiserum against fraction $1 \mathrm{~b}$ respectively. Fraction $1 \mathrm{~b}$ was, therefore, the subject for further study. 
Table 1. Intracellular killing of strain BS4 (agar) by human phagocytes: effect of antiserum (against whole organisms) absorbed with crude OMV of BS4 (agar), their sodium cholate $(1 \%, w / v)$ extract and fractions of the latter

The results of experiments 1 and 2, 3 and 4 , and 5 and 6 are representative of a total of 4,17 , and 4 experiments respectively with different batches of materials.

Expt no.

(phagocyte donor)

1. (CP)

3. (HL)

5. (RH)

6. (NP)
Antiserum*

$\overbrace{\begin{array}{c}\text { Protein } \\ (\mu \mathrm{g} \text { BSA } \\ \text { equiv. })\end{array}}^{\begin{array}{c}\text { Carbohydrate } \\ (\mu \mathrm{g} \text { glucose } \\ \text { equiv. })\end{array}} \quad \begin{gathered}\text { KDO } \\ (\mu \mathrm{g})\end{gathered}$

Viable gonococci in phagocyte deposits after $1 \mathrm{~h}$ at $37^{\circ} \mathrm{C}$ (\% of total microscopic count) $\ddagger$
$11 \cdot 1$

$<0.2$

4.9

$4 \cdot 0$

$7 \cdot 8$

$<0.2$

$8 \cdot 0$

$4 \cdot 4$

$34 \cdot 0$

$1 \cdot 0$

19.7

$10 \cdot 3$

$15 \cdot 1$

$4 \cdot 0$

0.8

$17 \cdot 0$

1.0

$17 \cdot 5$

11.0

$13 \cdot 0$

$2 \cdot 3$

$2 \cdot 0$

$34 \cdot 3$

$1 \cdot 5$

$28 \cdot 1$

$13 \cdot 4$

$25 \cdot 2$

$0 \cdot 9$

$12 \cdot 0$

$22 \cdot 1$

ND, Not determined.

* Treatment of gonococci with antiserum against BS4 (agar) before mixing with phagocytes as described by Parsons et al. (1981).

$\dagger$ Absorption was done as described in the text; the concentration of all absorbents was equivalent to $5 \times 10^{11}$ gonococci $\mathrm{ml}^{-1}$ and analyses for protein, carbohydrate and KDO were as described in the text.

$¥$ The phagocytosis test was as described in the text. Suspensions of human phagocytes $\left(10^{6} ;\right.$ about $80 \%$ PMN phagocytes) were mixed with $10^{6} \mathrm{BS} 4$ (agar) organisms ( $>60 \%$ viable) in Leighton tubes and, after incubating $\left(1 \mathrm{~h}, 37^{\circ} \mathrm{C}\right)$, viable and visual counts of gonococci and counts of total numbers of phagocytes were made as described by Parsons et al. (1981).

\section{Absence of antiserum-neutralizing activity in LPS prepared from BS4 (agar)}

The presence of LPS in fraction $1 \mathrm{~b}$ prompted an investigation into whether LPS itself was the determinant of resistance. Table 2 shows the antiserum-neutralizing activity of the cholate extracts and LPS preparations made from the same batches of BS4 (agar). The latter were tested at four times the concentration of the cholate extract in relation to the standard concentration of gonococci $\left(5 \times 10^{11} \mathrm{ml}^{-1}\right)$ because the extraction process could not be expected to yield a full recovery of LPS. The LPS preparations contained protein but far less than was in the cholate extracts (Table 1). No LPS preparation showed serum-neutralizing activity, indicating that the protein component of fraction $1 \mathrm{~b}$ contained the putative determinant of resistance. 


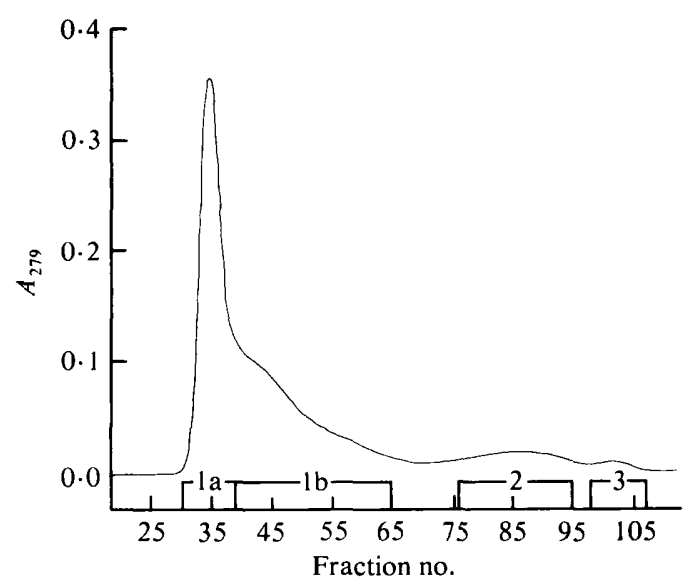

Fig. 1. Profile $\left(A_{279}\right)$ of the separation of sodium cholate $(1 \%, w / v)$ extract on Sephadex G75; this profile is typical of 17 similar experiments.

Table 2. Intracellular killing of strain BS4 (agar) by human phagocytes: effect of antiserum (against whole organisms) absorbed with LPS preparations from BS4 (agar)

The results are representative of six experiments with the different batches of material. For each experiment the cholate extract and LPS had been made from the same batch of BS4 (agar).

Expt no. (phagocyte donor)

1. (NP)

2. (JK)

3. (CP)

4. (HL)

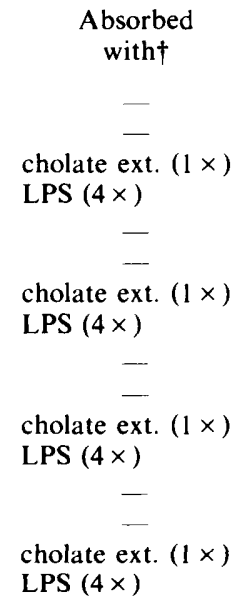

$\overbrace{\begin{array}{c}\text { Protein } \\ (\mu \mathrm{g} \text { BSA equiv. })\end{array}}^{\text {Analysis of absorbent } \mathrm{ml}^{-1}}$

$\begin{array}{rr} & \\ \text { ND } & \text { ND } \\ \text { ND } & 875 \\ & \\ 1714 & 903 \\ 333 & 1211 \\ & \\ 893 & 572 \\ 278 & 641 \\ & \\ & \\ 850 & 490 \\ 210 & 660\end{array}$

Viable gonococci in phagocyte deposits after $1 \mathrm{~h}$ at $37^{\circ} \mathrm{C}$ (\% of total microscopic count) $\ddagger$

ND, Not determined.

* As for Table 1.

+ As for Table 1 but the figures in parentheses give the concentration of the absorbent used in relation to that equivalent to $5 \times 10^{11}$ gonococci $\mathrm{ml}^{-1}$. $\ddagger$ As for Table 1 .

\section{Comparison of the proteins present in $O M V$, whole cholate extract and its fractions on $S D S-P A G E$}

Fig. 2 shows the protein patterns on SDS-PAGE for OMV, whole cholate extract and fractions $1 \mathrm{a}$ and $1 \mathrm{~b}$ from the Sephadex G75 column. To relate to the biological test, all materials were examined in amounts equivalent to the same numbers of gonococci (40-fold less than the standard number, $5 \times 10^{11}$ ), thus some channels were overloaded and others underloaded. The $\mathrm{OMV}$, the whole cholate extract and fraction la showed a full range of proteins including 


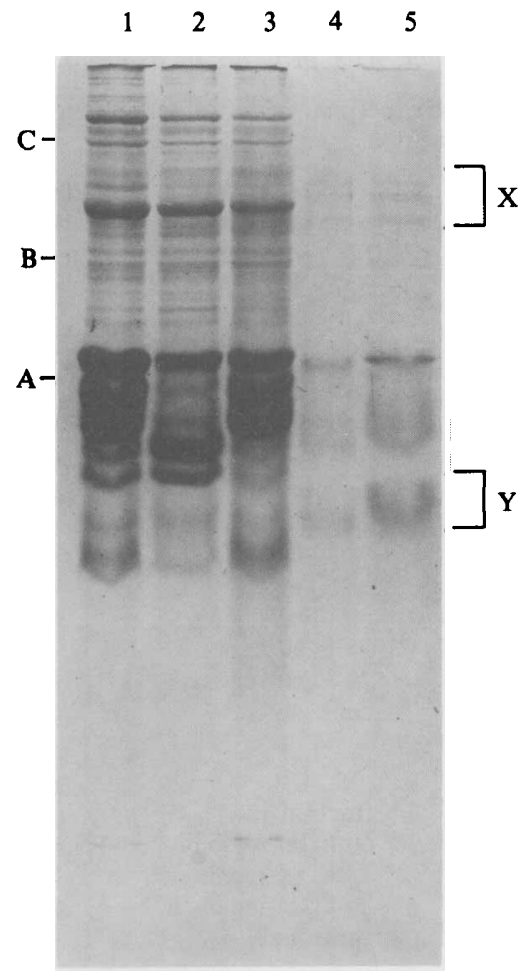

Fig. 2. SDS-PAGE of the OMV of BS4 (agar) (lane 1) their sodium cholate $(1 \%$,w/v) extract (lane 2) and fractions la (lane 3) and $1 \mathrm{~b}$ (lanes 4 and 5) from the Sephadex G75 column. The separating gel was $12.5 \%(\mathrm{w} / \mathrm{v})$ acrylamide. The amounts of material applied to the lanes were equivalent to $50 \mu \mathrm{l}$ of a suspension of $2.5 \times 10^{11}$ gonococci $\mathrm{ml}^{-1}$ except for lane 5 with fraction $1 \mathrm{~b}$ when five times this concentration was used.

proteins A, B and C (of about 35, 47 and $74 \mathrm{kDal}$ respectively; see Fig. 2) previously thought to be associated with phagocyte resistance (Parsons et al., 1982). In contrast, fraction 1 b showed much less total protein and fewer individual proteins even when five times the amount of material was examined (Fig. 2). The principal membrane proteins of $N$. gonorrhoeae (sizes around $35 \mathrm{kDal}$ ) were very much reduced in fraction $1 \mathrm{~b}$ compared with the OMV, cholate extract and fraction $1 \mathrm{a}$, thus indicating they were not associated with phagocyte resistance. Similarly, proteins A, B and $\mathrm{C}$ were much reduced or not detected in the biologically active fraction $1 \mathrm{~b}$. The proteins in fraction $1 \mathrm{~b}$ that appeared to be present in similar amounts in the equally biologically active fraction 1a, and in OMV and the cholate extract, were a group of proteins in the $60 \mathrm{kDal}$ region (marked $\mathrm{X}$ in Fig. 2) and one or more proteins in a diffuse band around $20 \mathrm{kDal}$ (marked $\mathrm{Y}$ in Fig. 2).

In two experiments in which a fraction $1 \mathrm{~b}$ obtained from the phagocyte-susceptible strain BSSH by the same method as that described for BS4 (agar) was examined at the standard concentration, and at five times that concentration, the groups of proteins associated with antiserum neutralization ( $\mathrm{X}$ and $\mathrm{Y}$, Fig. 2) were not detected.

\section{Antiserum-neutralizing effect of proteins of fraction 16 separated by SDS-PAGE}

In preparative experiments, the proteins demonstrated in fraction $1 \mathrm{~b}$ by SDS-PAGE that were associated with biological activity were eluted from regions (about $2 \mathrm{~cm}$ ) of the gels corresponding roughly to 60 and $20 \mathrm{kDal}$ (regions marked $\mathrm{X}$ and $\mathrm{Y}$ on Fig. 2) and, also, the principal outer membrane protein region around $35 \mathrm{kDal}$. The concentrated eluates were used to 
Table 3. Intracellular killing of strain BS4 (agar) by human phagocytes: effect of antiserum (against whole organisms) absorbed with proteins of fraction $1 b$ separated by SDS-PAGE

The results are representative of nine experiments with different batches of material. Fraction $1 \mathrm{~b}$ was omitted from the testing of experiment 4.

Expt no.

(phagocyte donor)

1. (CP)

2. (HL)

3. (JK)

4. (CP)

\begin{abstract}
Antiserum*
\end{abstract}

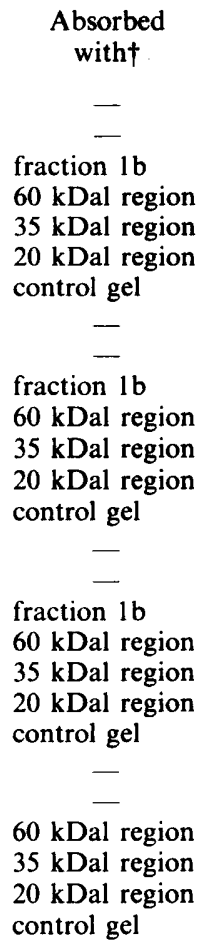

Viable gonococci in phagocyte
deposits after 1 h at $37{ }^{\circ} \mathrm{C}$
$(\%$ of total microscopic count $) \ddagger$

$12 \cdot 5$

$1 \cdot 4$

$15 \cdot 1$

$1 \cdot 6$

$3 \cdot 6$

$19 \cdot 1$

1.0

$25 \cdot 1$

$0 \cdot 5$

$7 \cdot 0$

$1 \cdot 4$

$0 \cdot 1$

12.9

$1 \cdot 1$

$7 \cdot 7$

$1 \cdot 0$

$5 \cdot 8$

$1 \cdot 1$

$2 \cdot 3$

$13 \cdot 9$

$2 \cdot 6$

$17 \cdot 7$

$1 \cdot 3$

$2 \cdot 7$

$2 \cdot 4$

$14 \cdot 0$

$2 \cdot 0$

* As for Table 1.

$\dagger$ Absorption was done as described in the text; the concentration of all absorbents was equivalent to $1 \times 10^{12}$ gonococci $\mathrm{ml}^{-1}$.

$\ddagger$ As for Table 1 .

absorb the antiserum against BS4 (agar) together with an eluate from a control portion of the gel; the results of four experiments are summarized in Table 3. Clearly the antiserum-neutralizing activity lies with the protein(s) of the $20 \mathrm{kDal}$ region.

\section{DISCUSSION}

Sodium cholate dissolved the putative determinant of resistance to phagocyte killing. When the extract was fractionated on Sephadex G75, the profile (Fig. 1) indicated a poor separation of components. Hence the roughly equal split of biological activity between the main peak (fraction 1a) and its shoulder (fraction $1 \mathrm{~b}$ ) was not surprising. However, the small protein content of fraction $1 \mathrm{~b}$ compared with that of the main peak (and the original cholate extract) was unexpected in view of the elution profile. The large difference in protein content may have been due to the presence of more undissociated complexes in fraction la than in fraction $1 \mathrm{~b}$.

The relatively high carbohydrate content in the biologically inactive later fractions 2 and 3 (Fig. 1) indicated that LPS might not be the putative determinant. Nevertheless, KDO as well as carbohydrate analysis showed that substantial amounts of LPS remained in fraction $1 \mathrm{~b}$, and, for this reason, crude LPS preparations from strain BS4 (agar) were examined for antiserumneutralizing activity. They proved inactive when examined at relatively high concentration 
(Table 2). Support for the non-involvement of LPS in the resistance of BS4 (agar) to intracellular killing also came from the fact that the pyocin-sensitivity pattern of BS4 (agar), an indication of LPS structure, was similar to that of the phagocyte-susceptible strain BSSH (Winstanley et al., 1984).

After the biological activity of fraction $1 \mathrm{~b}$ had been confirmed by showing that an antiserum raised against it neutralized the resistance of BS4 (agar) to phagocyte killing, its protein profile in SDS-PAGE was examined in comparison with those of fraction $1 \mathrm{a}$ and OMV and the cholate extract (Fig. 2). The SDS-PAGE was conducted on amounts of material equivalent to the same number of gonococci and relating to the amounts used in biological tests. Strikingly, it confirmed the lack of protein in fraction $1 \mathrm{~b}$ in relation to fraction $1 \mathrm{a}$ and indicated, in view of the roughly equal biological activity of the two fractions, that a significant purification of the putative determinant had been made in fraction $1 \mathrm{~b}$ despite the portents of the elution profile. The principal outer membrane proteins around $35 \mathrm{kDal}$ and the proteins $\mathrm{A}, \mathrm{B}$ and $\mathrm{C}$ that had previously been thought to be associated with phagocyte resistance were either in much lower concentration in fraction $1 \mathrm{~b}$ than in fraction $1 \mathrm{a}, \mathrm{OMV}$ and the cholate extract, or not detectable at the concentrations used. Hence, they were not associated with biological activity at this later stage in the fractionation. The proteins that were present in similar amounts in the biologically active fractions $1 \mathrm{a}$ and $1 \mathrm{~b}$ (and in the OMV and cholate extract) were a group of faintly staining proteins in the region of $60 \mathrm{kDal}$, and one or more proteins in a diffuse band in the region of $20 \mathrm{kDal}$. Both sets of proteins were not detected in two experiments with a corresponding fraction from the phagocyte-susceptible strain BSSH. Elution of the $20 \mathrm{kDal}$ and $60 \mathrm{kDal}$ regions of preparative gels together with the $35 \mathrm{kDal}$ region, which had the small content of principal outer membrane proteins, and subsequent testing in the phagocytosis tests, clearly showed that antibody-neutralizing activity was only in the $20 \mathrm{kDal}$ region.

This work has associated a diffuse faintly staining protein band in the region of $20 \mathrm{kDal}$ with the resistance of strain BS4 (agar) to killing by phagocytes. This is interesting in relation to the recent finding by Cannon et al. (1984) that a faintly staining outer membrane protein of a similar molecular weight - the $\mathrm{H} 8$ antigen - was present in many gonococcal and meningococcal strains but not in most non-pathogenic Neisseria species. This protein is a potential candidate for a vaccine because it is present in many strains. Final purification of our material and further research should reveal whether the diffuse band contains more than one protein and if there is any relationship between these proteins and the $\mathrm{H} 8$ antigen of Cannon et al. (1984). It should also strengthen the evidence of association between these proteins and resistance to killing by phagocytes towards that of causation.

We wish to thank Mrs J. D. Gem and Miss V. J. Holford for technical assistance, and also our blood donors.

\section{REFERENCES}

Cannon, J. G., Black, W. J., Nachamkin, I. \& Stewart, P. W. (1984). Monoclonal antibody that recognises an outer membrane antigen common to the pathogenic Neisseria species but not to most nonpathogenic Neisseria species. Infection and Immunity 43, 994-999.

Casey, S. G., Veale, D. R. \& Smith, H. (1979). Demonstration of intracellular growth of gonococci in human phagocytes using spectinomycin to kill extracellular organisms. Journal of General Microbiology 113, 395-398.

Heckels, J. E. (1977). The surface properties of Neisseria gonorrhoeae: isolation of the major components of the outer membrane. Journal of General Microbiology 99, 333-341.

LAEMMLI, U. K. (1970). Cleavage of structural proteins during the assembly of the head of bacteriophage T4. Nature, London 227, 680-685.
Parsons, N. J., Penn, C. W., Veale, D. R. \& Smith, H. (1979). More than one antigen contributes to the immunogenicity of Neisseria gonorrhoeae in the guinea pig subcutaneous chamber model. Journal of General Microbiology 113, 97-104.

Parsons, N. J., KWaAsi, A. A. A., Turner, J. A., Veale, D. R., Perera, V. Y., PenN, C. W. \& Smith, H. (1981). Investigation of the determinants of the survival of Neisseria gonorrhoeae within human polymorphonuclear phagocytes. Journal of General Microbiology 127, 103-112.

Parsons, N. J., Kwaasi, A. A. A., Perera, V. Y., Patel, P. V., Martin, P. M. V. \& Smith, H. (1982). Outer membrane proteins of Neisseria gonorrhoeae associated with survival within human polymorphonuclear phagocytes. Journal of General Microbiology 128, 3077-3081.

Penn, C. W., Sen, D., Veale, D. R., Parsons, N. J., 
SMITH, H. \& WITT, K. (1976). Morphological, biological and antigenic properties of Neisseria gonorrhoeae adapted to growth in guinea pig subcutaneous chambers. Journal of General Microbiology 97 , 35-43.

Penn, C. W., Veale, D. R. \& Smith, H. (1977). Selection from gonococci grown in vitro of a colony type with some virulence properties of organisms adapted in vivo. Journal of General Microbiology 100 , 147-158.

Trevelyan, W. E. \& Harrison, J. S. (1952). A micromethod for determination of carbohydrate. Biochemical Journal 50, 298-306.

Veale, D. R., Smith, H., Witt, K. \& Marshall, R. B. (1975). Differential ability of colonial types of Neisseria gonorrhoeae to produce infection and an inflammatory response in subcutaneous perforated plastic chambers in guinea pigs and rabbits. Journal of Medical Microbiology 8, 325-335.

Veale, D. R., Penn, C. W., Sutton, S. \& Smith, H. (1978). The effect of specific antiserum on the resistance of Neisseria gonorrhoeae to intracellular killing by phagocytes of human blood. Journal of General Microbiology 106, 129-136.
Veale, D. R., Goldner, M., Penn, C. W., Ward, J. \& SMITH, H. (1979). The intracellular survival and growth of gonococci in human phagocytes. Journal of General Microbiology 113, 383-393.

WESTPHAL, O. \& JANN, K. (1965). Lipopolysaccharide extraction with phenol water and further application of the procedure. Methods in Carbohydrate Chemistry 5, 83-89.

Winstanley, F. P., Blackwell, C. C., Tan, E. L., Patel, P. V., Parsons, N. J., Martin, P. M. V. \& SMITH, H. (1984). Alteration of pyocin sensitivity pattern of Neisseria gonorrhoeae is associated with induced resistance to killing by human serum. Journal of General Microhiology 130, I 303-1306.

Witt, K., Veale, D. R., Finch, H., Penn, C. W., Sen, D. \& SMITH, H. (1976a). Resistance of Neisseria gonorrhoeae grown in vivo to ingestion and digestion by phagocytes of human buffy coat. Journal of General Microbiology 96, 341-350.

WitT, K., Veale, D. R. \& SMith, H. (1976b). Resistance to ingestion and digestion of Neisseria gonorrhoeae by phagocytes of human buffy coat. Journal of Medical Microbiology 9, 1-12. 